Research Article

\title{
Sodium Silicate Catalyst for Synthesis Monoacylglycerol and Diacylglycerol-Rich Structured Lipids: Product Characteristic and Glycerolysis-Interesterification Kinetics
}

\author{
Inasanti Pandan Wangi ${ }^{1}$, Supriyanto Supriyanto ${ }^{1}$, Hary Sulistyo ${ }^{2}$, Chusnul Hidayat ${ }^{1, *}$ \\ 'Department of Food and Agricultural Product Technology, Faculty of Agricultural Technology, Universitas \\ Gadjah Mada, Jl. Flora No 1 Bulaksumur, Yogyakarta, Indonesia. \\ ${ }^{2}$ Department of Chemical Engineering, Faculty of Engineering, Universitas Gadjah Mada, Jl. Grafika No 2 \\ Yogyakarta, Indonesia.
}

Received: 30th December 2021; Revised: 22 nd February 2022; Accepted: 23rd February 2022 Available online: $2^{\text {nd }}$ March 2022; Published regularly: June 2022

\section{Abstract}

Sodium silicate as heterogeneous base catalysts is more environmentally friendly and easily separated by filtration. The objective of this research was to evaluate the activated sodium silicate as catalyst for synthesis of monoacylglycerol (MAG) and diacylglycerol (DAG)-rich structured lipids (SLs) from a palm olein-stearin blend. Sodium silicate was activated and functional group was characterized. Reaction was performed using $5 \%$ catalyst (w/w) at various reaction temperature $\left(70-120^{\circ} \mathrm{C}\right)$ for $3 \mathrm{~h}$ in a batch stirred tank reactor. Physical properties of SLs, such as melting point, slip melting point, and hardness of SLs were determined. Reaction kinetics were also evaluated. The results show that $\mathrm{Si}-\mathrm{O}$ bending was reduced and shifted to a $\mathrm{Si}-\mathrm{O}-\mathrm{Na}$ and $\mathrm{Si}-\mathrm{O}-\mathrm{Si}$ functional groups after sodium silicate activation. Temperature had a significant effect on SLs composition at higher than $90{ }^{\circ} \mathrm{C}$. An increase in temperature produced more MAG, resulting in better product physical properties. The best reaction condition was at $110{ }^{\circ} \mathrm{C}$. Rate constants and the Arrhenius equation were also obtained for each reaction step. In summary, the activated sodium silicate catalyzed glycerolysis-interesterification reaction, which produced MAG and DAG at temperature higher than $90^{\circ} \mathrm{C}$. Therefore, the physical properties of SLs were improved.

Copyright (C 2022 by Authors, Published by BCREC Group. This is an open access article under the CC BY-SA License (https://creativecommons.org/licenses/by-sa/4.0).

Keywords: Glycerolysis-Interesterification; Structured Lipids; Monoacylglycerol and Diacylglycerol; Heterogeneous Base Catalyst; Reaction Kinetics

How to Cite: I.P. Wangi, S. Supriyanto, H. Sulistyo, C. Hidayat (2022). Sodium Silicate Catalyst for Synthesis Monoacylglycerol and Diacylglycerol-Rich Structured Lipids: Product Characteristic and Glycerolysis-

Interesterification Kinetics. Bulletin of Chemical Reaction Engineering \& Catalysis, 17(2), 250-262 (doi: 10.9767/bcrec.17.2.13306.250-262)

Permalink/DOI: https://doi.org/10.9767/bcrec.17.2.13306.250-262

\section{Introduction}

Structured lipids (SLs) are fats that have been chemically or enzymatically modified from their natural form to meet food and nutritional needs. The scope of SLs includes the manufacture of triacylglycerol (TAG), monoacylglycerol

\footnotetext{
* Corresponding Author.

Email: chusnulhi@ugm.ac.id (C. Hidayat);

Telp: +62-274-589797, Fax: +62-274-589797
}

(MAG), diacylglycerol (DAG), and phospholipids [1]. MAG and DAG are emulsifiers that are widely applied to food products, which is as much as $75 \%$ of the total world use of emulsifiers and is also commonly used in bakery, margarine, dairy, and confectionery products because of their emulsifying, stabilizing, and conditioning properties [2,3]. MAG and DAG have high melting points so that they are solid at room temperature [4]. The nature of MAG and 
DAG can be utilized as SLs to increase the melting point (MP) and hardness of the resulting product.

The synthesis of SLs containing MAG and DAG is usually carried out by glycerolysis, in which oil reacts with glycerol to produce MAG and DAG products [3]. However, glycerolysis is usually only performed by one type of fat/oil blend. Production of MAG and DAG-rich SLs from blended oil can be carried out by simultaneously combining the glycerolysis reaction with interesterification, called the glycerolysisinteresterification reaction [5,6]. Glycerolysisinteresterification is a simultaneous reaction between glycerolysis and interesterification. This combination can improve the physicochemical properties of the desired product $[5,6]$.

Some importance kinetic studies on glycerolysis-interesterification are to understand the reaction mechanism, develop a mathematical model of the reaction rate, and evaluate the operating parameters of the system [7]. Reaction kinetic studies are generally carried out by Arrhenius equation, in which different operating conditions lead to various Arrhenius parameters [8-14]. Although the reaction kinetic studies of numerous types of fat and oil had been widely reported previously, the analysis of blended fat or oil has not been much reported yet [12-15]. Therefore, it will be an interesting subject to further study.

MAG and DAG synthesis can be carried out enzymatically or chemically. Chemical processes using heterogeneous base catalysts provide a more efficient and environmentally friendly approach. They were (i) easily separated by filtration, (ii) could avoid the formation of byproducts, (iv) did not require a neutralization step to stop the reaction, and (v) could be reused for subsequent processes [16,17]. Several studies using heterogeneous base catalysts, such as $\mathrm{MgO} / \mathrm{Mg}$-Al hydrotalcite, hydrotalcite + $\mathrm{K}_{2} \mathrm{CO}_{3}$, and $\mathrm{MgO}$ supported - $\mathrm{KOH}$ catalyst, resulted in relatively high yields [16-18]. One of the heterogeneous base catalysts that can be used is the sodium silicate (Na-silicate) catalyst. Sodium silicate catalyst is a heterogeneous base catalyst. It has high catalytic activity and has characteristics that resemble a supported-solid base catalyst. This was shown from several studies that have been carried out on the manufacture of biodiesel using the catalyst $[8,19,20]$. To the best of our knowledge, the application of sodium silicate catalyst in SLs synthesis and/or glycerolysis process has limitedly been used. Therefore, this research was conducted using a sodium silicate base catalyst for the MAG and DAG-rich SLs synthesis through the glycerolysis-interesterification reaction.

The purpose of this research was to evaluate the reaction kinetics and acyl glycerol profile of the glycerolysis-interesterification process using activated sodium silicate. In this research, MAG and DAG-rich structured lipids were synthesized from a palm stearin-olein blend using activated sodium silicate as the heterogeneous base catalyst. The reactions were modeled, and their rate constants were determined based on the reaction model. The effect of temperature on rate constants was predicted using the Arrhenius equation. Furthermore, the physical properties, such as melting profile and hardness of the product, and the interaction between the sodium silicate catalyst and SLs products were also evaluated.

\section{Materials and Methods}

\subsection{Materials}

Refined Bleached and Deodorized Palm Stearin (RBDPS) (IV 38.56 I2 / $100 \mathrm{~g}$ fat) and Palm Olein were obtained from PT. Sinar Mas (Surabaya, Indonesia). Glycerol, $\mathrm{NaOH}$, and silica gel were obtained from Merck KGaA (Darmstadt, Germany). A molecular sieve was obtained from Sigma-Aldrich (Missouri, USA).

\subsection{Sodium Silicate Catalyst Activation}

The sodium silicate was activated according to Perdana et al. [20]. Sodium hydroxide $(\mathrm{NaOH})$ was weighed as much as $10 \mathrm{~g}$, then dissolved in $10 \mathrm{~mL}$ of aquadest and stirred until homogeneous. The silica gel $(7.5 \mathrm{~g})$ was added gradually into the $\mathrm{NaOH}$ solution while stirring until a gel was formed. The gel was added to the porcelain crucible and heated in the furnace at $400{ }^{\circ} \mathrm{C}$ for $3 \mathrm{~h}$. The activated gel was crushed with mortar. The result was sodium silicate powder, which could be directly used as a catalyst in the glycerolysis-interesterification reaction.

\subsection{Glycerolysis-Interesterification Reaction at} Various Temperature

The glycerolysis-interesterification reaction process was modified from Subroto et al. [5]. Palm stearin and palm olein ratio of $1: 4(\mathrm{w} / \mathrm{w})$ were blended, then called oil. The oil was reacted with glycerol with a molar ratio of oil : glycerol $=1: 2$. Sodium silicate catalyst was added as much as $5 \%(\mathrm{w} / \mathrm{w}$ oil) and molecular sieve was added as much as $12 \%(\mathrm{w} / \mathrm{w}$ total reactant). The reaction was performed in a batch reactor at various temperatures $(70,80,90$, 
100, 110 , and $120^{\circ} \mathrm{C}$ ) and a stirring speed of $200 \mathrm{rpm}$ for $3 \mathrm{~h}$. Samples were taken at 0, 5, $10,15,30,45,60,75,90,120,150$, and 180 min. The sample was then analyzed to determine TAG, MAG, and DAG concentrations. The properties of SLs products were also analyzed.

\subsection{Characterization of Sodium Silicate Cata- lyst}

Molecular structure and functional groups of sodium silicate catalyst were analyzed using Fourier Transfer Infrared (FTIR) Spectroscopy type 8201PC, Shimadzu Co., Japan, with a scanning range of $280-4000 \mathrm{~cm}^{-1}$.

The total basicity of sodium silicate catalyst was analyzed using the Tanabe and Yamaguchi method [21,22]. About $20 \mathrm{~mL}$ of Benzene and 1 $\mathrm{mL}$ Bromthymol Blue indicator solution were added to a $100 \mathrm{~mL}$ Erlenmeyer flask. About $100 \mathrm{mg}$ of $100-200$ mesh sodium silicate catalyst was added to the solution. Sample was then titrated with $0.1 \mathrm{~N}$ Benzoic acid solutions until the green color disappeared.

\subsection{Analysis of Acyl Glycerol Concentrations}

The analysis of acyl glycerol was performed according to Subroto et al. [5]. The MAG, DAG, and TAG concentrations in each sample were analyzed using the Thin Layer Chromatography (TLC) scanner type Camag Automatic TLC Scanner III Dummy S/N (1.14.16) with Camag WinCATS software planar chromatography at wavelength $629 \mathrm{~nm}$. Hexane, diethyl ether, and acetic acid (80:20:2, v/v/v) mixed solvent system was used as the mobile phase.

$$
\begin{aligned}
& {\left[\begin{array}{l}
\mathrm{OCOR} \\
\mathrm{OCOR}
\end{array}+\left[\begin{array} { l } 
{ \mathrm { OH } } \\
{ \mathrm { OCH } } \\
{ \mathrm { OH } }
\end{array} \underset { \mathrm { k } _ { 2 } } { \stackrel { \mathrm { k } _ { 1 } } { \rightleftarrows } } \left[\begin{array}{l}
\mathrm{OH} \\
\mathrm{OH}
\end{array}+\left[\begin{array}{l}
\mathrm{OCOR} \\
-\mathrm{OH} \\
\mathrm{OCOR}
\end{array}\right.\right.\right.\right.} \\
& \text { TAG Glycerol MAG DAG } \\
& { }_{-\mathrm{OCOR}}^{\mathrm{OCOR}}+\left[\begin{array} { l } 
{ \mathrm { OH } } \\
{ - \mathrm { OH } } \\
{ \mathrm { OH } }
\end{array} \stackrel { \mathrm { k } _ { 3 } } { \rightleftarrows } \left[\begin{array}{l}
\mathrm{OH} \\
-\mathrm{OH} \\
\mathrm{OCOR}
\end{array}+\left[\begin{array}{l}
\mathrm{OH} \\
-\mathrm{OH} \\
\mathrm{OCOR}
\end{array}\right.\right.\right. \\
& \text { DAG Glycerol MAG MAG } \\
& \underset{\mathrm{OCOR}}{\mathrm{OCOR}}+\underset{\mathrm{OCOR}}{-\mathrm{OCOR}} \underset{\mathrm{OH}}{\stackrel{\mathrm{k}_{5}}{\rightleftarrows}}\left[\begin{array}{l}
\mathrm{OH} \\
-\mathrm{OCOR} \\
\mathrm{OCOR}
\end{array}+\left[\begin{array}{l}
\mathrm{OH} \\
-\mathrm{OCOR} \\
\mathrm{OCOR}
\end{array}\right.\right. \\
& \text { TAG MAG DAG DAG }
\end{aligned}
$$

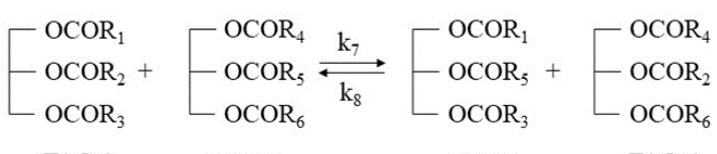

$$
\begin{aligned}
& \begin{array}{llll}
\text { TAG } 1 & \text { TAG } 2 & \text { TAG } 3 & \text { TAG } 4
\end{array}
\end{aligned}
$$

Figure 1. Schematic model of glycerolysisinteresterification reaction.

\subsection{Reaction Kinetics Model}

The glycerolysis-interesterification reaction was modeled as a combination of glycerolysis and interesterification reactions (Figure 1). In this reaction, TAG reacts with glycerol to produce MAG and DAG, namely the glycerolysis process. It can also react with another type of TAG with a different fatty acid profile, namely interesterification. This reaction can increase the possibility of the formation of desired fat because the obtained results are in the form of a mixture of MAG, DAG, and TAG SLs, which all play a role in shaping the physical, chemical, and functional properties of the targeted fat [5].

In this model, 4 possible reactions occur at the same time (Figure 1), in which reaction (1) to (3) represent the glycerolysis process and reaction (4) represents the interesterification. In the glycerolysis process, equation (1) is the initial reaction, then continued with Equation (2) which DAG byproduct reacts with the excess glycerol. If the MAG production is excess, the reaction will continue to Equation (3) which MAG reacts with the raw material to produce DAG. In the interesterification, the acyl migration only occurs between TAG.

The following assumptions were made in order to generate the reaction kinetics model: (a) Equation (1) expressed as the initial reaction can be considered as an irreversible reaction because of the excess of glycerol and low product concentration. Thus, the reversible reaction (represented as $k_{2}$ ) was neglected; (b) Since chemical catalyst leads to random glycerolysisinteresterification, the acyl migration on the glycerol backbone was challenging to identify because it varies widely over time. Thus, the acyl migration during the reaction was not analyzed, and the reaction kinetics determination was based on glycerolysis only; (c) A molecular sieve was used in this reaction. Thus, the forming of free fatty acid (FFA) during the reaction was neglected; (d) Catalyst was homogeneously dispersed in the system due to the mixing of reaction mixture at $200 \mathrm{rpm}$. Thus, mass transfer rate from the reactant to the catalyst can be neglected.

The following differential rate equations can then be used to describe the rate of change in concentration for each of the reaction components.

$$
\begin{aligned}
\frac{d C_{M A G}}{d t}= & k_{1} C_{T A G} C_{G l y}+2 k_{3} C_{D A G} C_{G l y}-2 k_{4} C_{M A G}^{2} \\
& -k_{5} C_{T A G} C_{M A G}+k_{6} C_{D A G}^{2}
\end{aligned}
$$




$$
\begin{aligned}
& \frac{d C_{D A G}}{d t}=k_{1} C_{T A G} C_{G l y}-k_{3} C_{D A G} C_{G l y}+k_{4} C_{M A G}^{2} \\
& +2 k_{5} C_{T A G} C_{M A G}-2 k_{6} C_{D A G}^{2} \\
& \frac{d C_{T A G}}{d t}=-k_{1} C_{T A G} C_{G l y}-k_{5} C_{T A G} C_{M A G}+k_{6} C_{D A G}^{2} \\
& \frac{d C_{G l y}}{d t}=-k_{1} C_{T A G} C_{G l y}-k_{3} C_{D A G} C_{G l y}+k_{4} C_{M A G}^{2}
\end{aligned}
$$

where, $C$ is the concentration for each substance. Gly refers to glycerol. A computational code for the parameter estimation technique was written and implemented. The differential equations were solved with the ode15s subroutine, and the objective function was minimized with the lsqnonlin nonlinear data-fitting optimization subroutine.

The relationship between temperature and reaction rate constant was shown by the Arrhenius Equation (9).

$$
k=A \exp \left(-\frac{E a}{R T}\right)
$$

where, $k$ is the reaction rate constant, $A$ is the exponential factor, $E a$ is the activation energy, $R$ is the ideal gas constant, and $T$ is the reaction temperature. From the Arrhenius Equation (9) it can be linearized as in Equation (10), so that the value of the activation energy $(E a)$ and the exponential factor $(A)$ can be obtained.

$$
\ln k=\ln A-\frac{E a}{R} \frac{1}{T}
$$

The obtained Arrhenius parameters were used to predict the MAG, DAG and TAG model at various temperature.

\subsection{Analysis of Product Melting Point and Slip Melting Point}

The slip melting point (SMP) analysis followed the AOCS Official Method Cc 3-25, and MP analysis followed the AOCS Official Method Cc 1-25 44, 45. Melted samples were inserted into a hematocrit tube about $1 \mathrm{~cm}$ height and then refrigerated overnight. Refrigerated samples were then heated gradually with the temperature increasing rate of about 0.5 ${ }^{\circ} \mathrm{C} /$ min until the samples flowed through the tube and changed into a clear liquid [23].

\subsection{Analysis of Product Hardness}

The product hardness was analyzed using the TA.XT Plus (Stable Micro Systems) type texture analyzer, with diameter probe 12.7 $\mathrm{mm}$. Samples were prepared by melting the products at $80{ }^{\circ} \mathrm{C}$ for $15 \mathrm{~min}$, then placed in a sample cup for about $1.5 \mathrm{~cm}$ in depth and con- tinued by placing the samples at room temperature until hardened and then keeping the samples in a refrigerator (around $10{ }^{\circ} \mathrm{C}$ ) for approximately $18 \mathrm{~h}$. Before measurement, samples were taken out from the refrigerator and thawed for about $1 \mathrm{~h}$. Measurements were performed at room temperature [5].

\subsection{Statistical Analysis}

A one-way analysis of variance (ANOVA) was used to analyze the data. Tukey's test was used to identify the difference between samples. P-value of $<0.05$ were considered significant.

\section{Results and Discussion}

\subsection{Characteristics of Sodium Silicate Catalyst}

The silica powder and the activated sodium silicate catalyst were analyzed using Fourier Transform Infra-Red (FTIR) spectroscopy to determine the functional structure applied on the catalyst surface. The result is shown in Figure 2. The dominant functional group in silica powder was silicate ion, represented as a downward peak at a wavelength value $\sim 1100$ $\mathrm{cm}^{-1}$ (Figure 2(A)). An absorption band of $\mathrm{Si}-\mathrm{O}$ bending also occurred at $\sim 470 \mathrm{~cm}^{-1}[19,24]$. After the silica powder was reacted and activated into an activated sodium silicate catalyst, the intensity of the silicate ion and $\mathrm{Si}-\mathrm{O}$ bending was reduced, shifted into a $\mathrm{Si}-\mathrm{O}-\mathrm{Na}$ and Si-O-Si functional groups, shown by a sharp downward peak at $\sim 1000 \mathrm{~cm}^{-1}$ and $\sim 890 \mathrm{~cm}^{-1}$, respectively (Figure $2(\mathrm{~B})$ ).

These results prove that the activation process improved the structure of sodium silicate. The $\mathrm{Na}^{+}$ions were organized in various patterns around the non-bridging oxygen after activation [25]. Consequently, the ion exchange process becomes easier and can lead to a higher catalytic activity. Besides, the formation of the $\mathrm{Si}-\mathrm{O}-\mathrm{Si}$ group during the activation process shows that the $\mathrm{SiO}_{4} 4^{--}$tetrahedral shape changed from low polymerization conditions to high polymerization conditions. Changing the sodium silicate catalyst group to a more stable condition can provide a higher reaction conversion $[19,25]$. These transformations prove that the sodium silicate catalyst production and activation process was successful and can be used as a catalyst.

On the other hand, the total basicity of the activated sodium silicate catalyst was $9.19 \pm 0.08 \mathrm{mmol} / \mathrm{g}$. This result was lower than the total basicity value reported by Guo et al. [19] at the same operating conditions. It is sug- 
gested that the difference in basicity value is due to the difference in the source of silica gel. Although it has a slight difference, the basicity value of the activated sodium silicate catalyst was still higher than other heterogeneous base catalysts $[21,22,26]$. A higher basicity value may result in a higher conversion rate [19].
3.2 Conversion of Acyl Glycerol at Various Reaction Temperature

Glycerolysis-Interesterification was conducted in a batch stirred tank reactor at various temperatures using the activated sodium silicate catalyst. The conversions of TAG, $\mathrm{MAG}$, and DAG at each variation are shown in
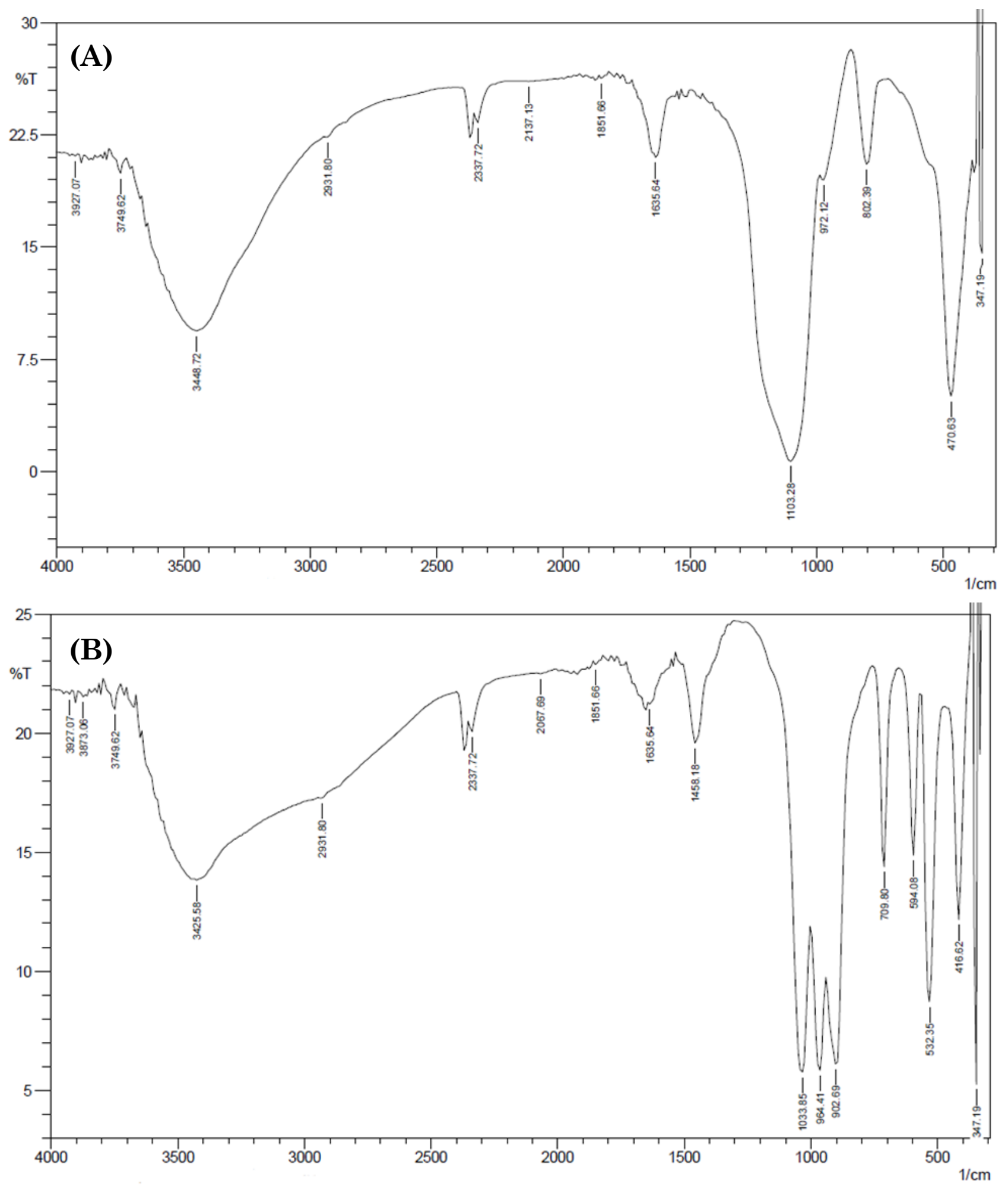

Figure 2. Functional structure of silica powder (A) and activated sodium silicate catalyst (B). 
Figure 3. Most of them implied that the TAG concentration decreased while the concentrations of MAG and DAG increased with the increasing time. This result proves that the glycerolysis-interesterification reaction using the activated sodium silicate catalyst produce a combination of MAG, DAG, and TAG in the products.
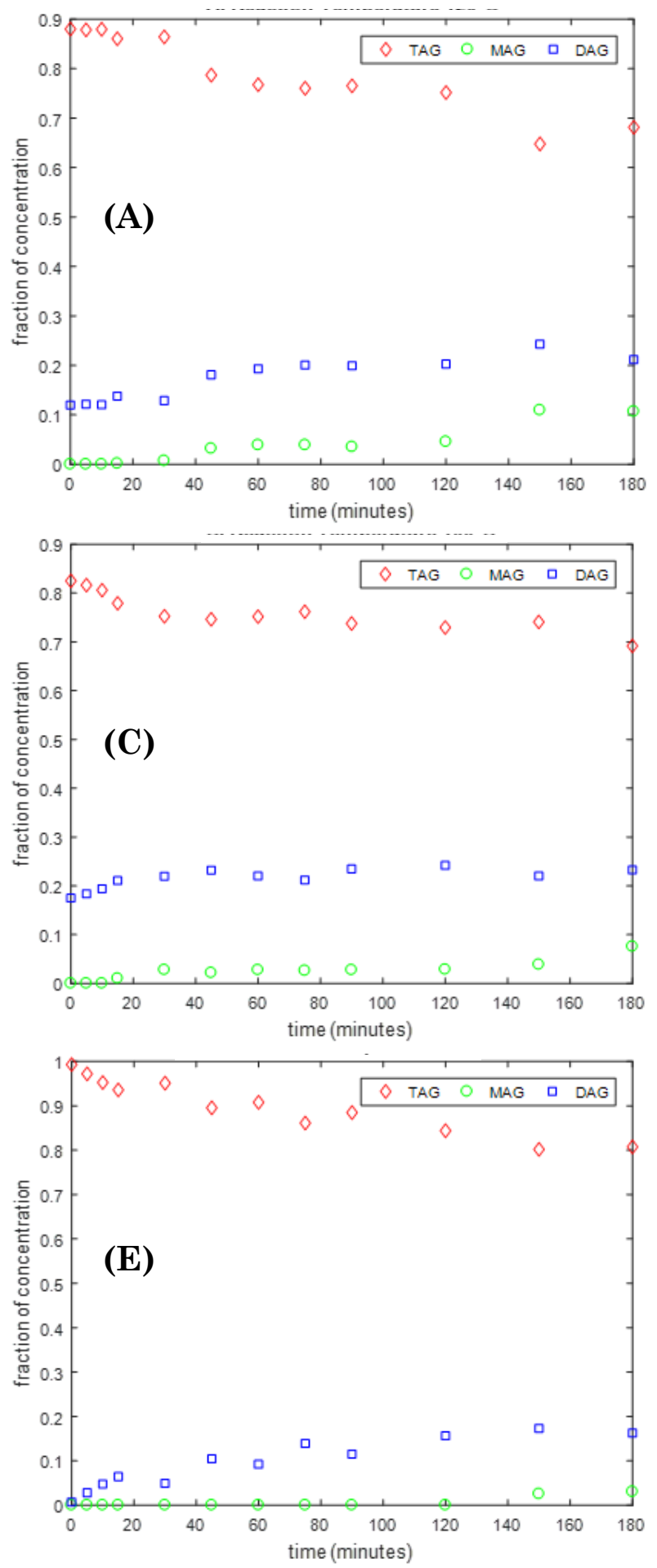

MAG and DAG concentrations were lower than TAG concentration. It shows that not all TAGs were converted to MAG and DAG. Also, that TAG was still the dominant component in the product. At $90{ }^{\circ} \mathrm{C}$ and above, both the decrease in TAG and the increase in MAG and FFA were optimum. The high temperature helps catalysts extract hydrogen from glycerol
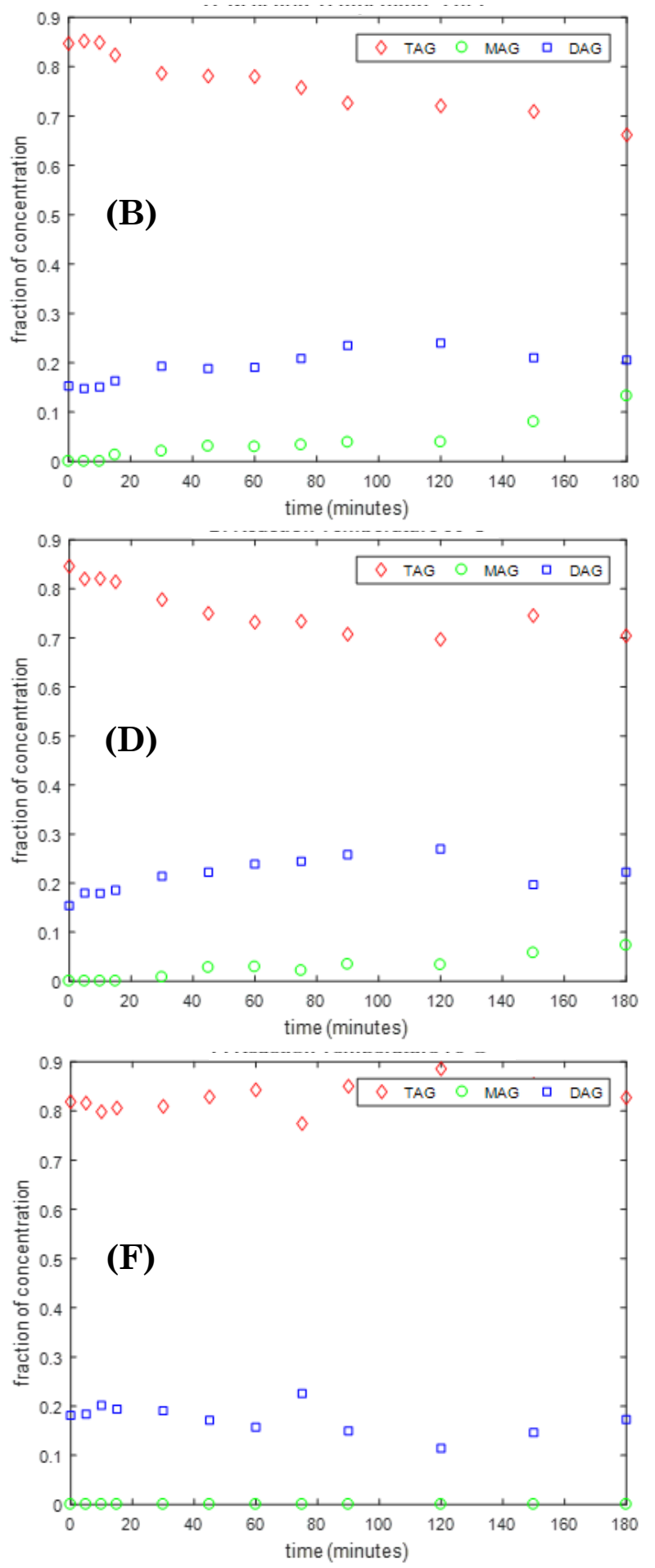

Figure 3. Conversion of TAG, MAG, and DAG at reaction temperature $120^{\circ} \mathrm{C}(\mathrm{A}), 110{ }^{\circ} \mathrm{C}(\mathrm{B}), 100{ }^{\circ} \mathrm{C}$ $(\mathrm{C}), 90^{\circ} \mathrm{C}(\mathrm{D}), 80^{\circ} \mathrm{C}(\mathrm{E})$ and $70{ }^{\circ} \mathrm{C}(\mathrm{F})$; stirring speed $200 \mathrm{rpm}$; and reaction time $3 \mathrm{~h}$. 
[28]. At $110^{\circ} \mathrm{C}$ and $120^{\circ} \mathrm{C}$, the TAG, MAG, and DAG contents were at maximum value, which converted to $65 \%, 10 \%$, and $25 \%$, respectively. Temperature $110{ }^{\circ} \mathrm{C}$ was chosen to be the bestoperating condition because it requires lower energy, although it has a similar result with $120^{\circ} \mathrm{C}$.

It is suggested that the catalytic mechanism for glycerolysis-interesterification using the activated sodium silicate follows several steps $[25,27]$. The first step was the triglyceride enolate anion formation through alpha hydrogen abstraction by sodium silicate catalyst. The triglyceride enolate anion was then reacted with glycerol, leading to an ester interchange to form MAG and diglyceride anion. Finally, the proton was then transferred to diglyceride anion to form DAG in 2 possible ways: one is from the catalyst, and the other is from glycerol to produce more MAG. In addition, the triglyceride enolate anion was also able to react with MAG to produce DAG. This phenomenon may explain why the DAG value has a relatively stable value through time because it was always consumed and produced simultaneously during the reaction. The triglyceride enolate anion was also able to react with TAG as well to perform an interesterification mechanism. A beta-keto ester was formed during the process, which led to a TAG formation with a different fatty acid profile.

However, lower reaction temperature shows the opposite results. At the reaction temperature below $90{ }^{\circ} \mathrm{C}$, the maximum reduction of TAG was around $80 \%$, and the maximum rise of MAG was only about 3\%. These results showed that low temperatures (especially $70^{\circ} \mathrm{C}$ and below) were insufficient to provide the appropriate MAG and DAG in products. Similar results were also reported by Zhong et al. [16] that $80^{\circ} \mathrm{C}$ was required and suitable to produce DAG by glycerolysis using $\mathrm{KOH}-\mathrm{MgO}$ supported catalyst. Zhong et al. [16] also reported that $\mathrm{CaO}, \mathrm{MgO}$, and calcium hydroxide $\left(\mathrm{Ca}(\mathrm{OH})_{2}\right)$ catalysts were not effective for glycerolysis at a temperature lower than $100{ }^{\circ} \mathrm{C}$.
3.3 Composition of TAG, MAG, and DAG in Structured Lipid Products

The composition of TAG, MAG, and DAG in the end products at each reaction temperature is presented in Table 1. It could be seen at high temperature, the TAG value were significantly different than the value at low temperature (Table 1). Lower TAG value shows that some of TAG were converted to MAG or DAG as products. These results proved that a higher reaction temperature could convert more TAG into products than a lower reaction temperature.

The MAG value differed significantly in every reaction temperature. The MAG content at 120 and $110^{\circ} \mathrm{C}$ had the highest value, while 80 ${ }^{\circ} \mathrm{C}$ had the lowest value. These results also proved that a higher reaction temperature could produce more MAG than a lower reaction temperature. No MAG content was produced at $70{ }^{\circ} \mathrm{C}$. It proved that this temperature was insufficient to initiate the glycerolysisinteresterification reaction. The reaction using low temperature had been previously reported by Subroto et al. [5]. The TAG content could be decreased up to $60 \%$, MAG and DAG content increased up to $12 \%$ and $28 \%$, respectively, using immobilized $C$. antarctica lipase as the catalyst at $50{ }^{\circ} \mathrm{C}$ for $24 \mathrm{~h}$. Although it is possible to produce the SLs using low temperatures, a longer reaction time was needed. Thus, a higher temperature is still preferable in MAG and DAG-rich SLs production.

The DAG value for each reaction was not significantly different (Table 1 ). The value of DAG at the end of the reaction was also not much different from the initial value (Figure $3)$. This shows that there is only a small increase in the DAG value at the end product. In glycerolysis reaction, DAG is an intermediate product that will react with glycerol to produce MAG (Figure 1). However, the accumulation of MAG would react with the excess TAG to produce DAG, as the result, there is only a slight increase in the amount of DAG at the end of the reaction.

Table 1. Composition of TAG, MAG and DAG in structured lipid products.

\begin{tabular}{cccc}
\hline Reaction Temperature $\left({ }^{\circ} \mathrm{C}\right)$ & TAG (\%) & MAG (\%) & DAG (\%) \\
\hline 120 & $68.14 \pm 1.84^{\mathrm{a} 1)}$ & $10.68 \pm 0.76^{\mathrm{ab}}$ & $21.18 \pm 1.97^{\mathrm{a}}$ \\
110 & $66.19 \pm 3.15^{\mathrm{a}}$ & $13.26 \pm 1.26^{\mathrm{a}}$ & $20.55 \pm 1.89^{\mathrm{a}}$ \\
100 & $71.03 \pm 2.61^{\mathrm{a}}$ & $6.89 \pm 0.95^{\mathrm{c}}$ & $22.09 \pm 1.65^{\mathrm{a}}$ \\
90 & $70.44 \pm 5.54^{\mathrm{a}}$ & $7.30 \pm 0.85^{\mathrm{bc}}$ & $22.26 \pm 4.70^{\mathrm{a}}$ \\
80 & $80.74 \pm 0.46^{\mathrm{b}}$ & $3.03 \pm 0.54^{\mathrm{d}}$ & $16.23 \pm 0.08^{\mathrm{a}}$ \\
70 & $82.72 \pm 5.21^{\mathrm{b}}$ & $0.00 \pm 0.00^{\mathrm{d}}$ & $17.28 \pm 5.21^{\mathrm{a}}$ \\
\hline
\end{tabular}

1) Different letters indicated significantly different values for each column $(p<0.05)$ 
3.4 Physical Properties of Monoacylglycerol and Diacylglycerol-Rich Structured Lipids

The tested physical properties of the structured lipid products were SMP, MP, and product hardness. Results are shown in Table 2. Samples were compared with the previous data from Subroto et al. [5]. Compared to Palm Stearin-Palm Olein (PS-PO) blend, samples produced by glycerolysis-interesterification have significantly higher SMP and MP values (Table 2). SLs products had 1.34-1.46 times higher and 1.36-1.52 times higher SMP and MP than the PS-PO blend, respectively.

It can also be seen that samples produced in higher reaction temperatures have significantly different SMP and MP values. The previous discussion from Figure 2 implied that higher reaction temperature leads to more MAG and DAG production. MAG and DAG have a higher MP than TAG, ranging from $55.5^{\circ} \mathrm{C}$ to $77.0^{\circ} \mathrm{C}$ depending on the type of fatty acid. The presence of MAG and DAG will contribute to the increase and variety of the melting profile of the structured lipid products, while the PS-PO blend did not contain any MAG $[4,5]$.

Product hardness value can also be seen in Table 2. PS-PO blend showed a drastically lower hardness value than the product with glycerolysis-interesterification at any reaction temperature, ranging from 4.65 to 15.90 -fold increase. Some samples from higher reaction temperatures (with significantly higher MAG and DAG content) also had a relatively higher hardness value. This issue happens because MAG and DAG are solid at room temperature, so the presence of MAG and DAG will increase the hardness of the structured lipid products [4].

At temperature $120{ }^{\circ} \mathrm{C}, \mathrm{MP}$ and hardness value were significantly lower than the value at $110^{\circ} \mathrm{C}$. These results could happen because random interesterification between TAG from PS and TAG from PO also occurred in this system. Depending on the iodine value, PS contains TAG with the structure of palmitateoleate-palmitate (p-o-p), palmitate-oleateoleate (p-o-o) and palmitate-palmitatepalmitate (p-p-p) fatty acids around 27.5$46.5 \%, 12.9-31.5 \%$ and $14.3-37.4 \%$, respectively. Whereas the TAG structure of PO consists of p-o-p, p-o-o and p-p-p around 28.7-40.9\%, $24.5-43.7 \%$ and $2.4-3.9 \%$, accordingly [29-31]. As mentioned earlier, the fatty acid type could affect the melting properties of the TAG, MAG, or DAG [4]. The random interesterification at $120{ }^{\circ} \mathrm{C}$ may produce a certain fatty acid profile that has lower MP properties. Thus, the melting profile and hardness can fluctuate for each reaction temperature.

3.5 Reaction Rate Constant and Arrhenius Parameters

At a reaction temperature of $70{ }^{\circ} \mathrm{C}$ (Table 1), MAG could not be formed under these oper-

Table 2. Physical properties of structured lipid products.

\begin{tabular}{cccc}
\hline $\begin{array}{c}\text { Reaction temperature } \\
\left({ }^{\circ} \mathrm{C}\right)\end{array}$ & $\begin{array}{c}\text { Slip Melting Point } \\
\left({ }^{\circ} \mathrm{C}\right)\end{array}$ & $\begin{array}{c}\text { Melting Point } \\
\left({ }^{\circ} \mathrm{C}\right)\end{array}$ & $\begin{array}{c}\text { Hardness } \\
(\mathrm{N})\end{array}$ \\
\hline 120 & $55.95 \pm 0.07^{\mathrm{a} 1)}$ & $59.90 \pm 0.28^{\mathrm{a}}$ & $23.89 \pm 0.07^{\mathrm{a}}$ \\
110 & $54.50 \pm 0.85^{\mathrm{ab}}$ & $65.45 \pm 0.64^{\mathrm{b}}$ & $28.93 \pm 0.08^{\mathrm{b}}$ \\
100 & $54.75 \pm 0.35^{\mathrm{ab}}$ & $67.10 \pm 0.28^{\mathrm{c}}$ & $14.31 \pm 0.02^{\mathrm{c}}$ \\
90 & $51.75 \pm 0.35^{\mathrm{b}}$ & $65.15 \pm 0.21^{\mathrm{b}}$ & $12.35 \pm 0.52^{\mathrm{d}}$ \\
80 & $51.30 \pm 0.14^{\mathrm{b}}$ & $63.10 \pm 0.42^{\mathrm{d}}$ & $14.27 \pm 0.77^{\mathrm{c}}$ \\
70 & $53.90 \pm 1.98^{\mathrm{ab}}$ & $60.10 \pm 0.42^{\mathrm{a}}$ & $8.30 \pm 0.53^{\mathrm{e}}$ \\
$50^{2)}$ & $38.67 \pm 0.29$ & $44.67 \pm 0.29$ & $5.63 \pm 0.59$ \\
PS-PO Blend ${ }^{2)}$ & $38.17 \pm 0.29$ & $44.00 \pm 1.00$ & $1.82 \pm 0.31$ \\
\hline
\end{tabular}

1) Different letters indicated significantly different values for each column $(p<0.05)$

2) Reference: Subroto et al. [5]

Table 3. Reaction rate constant and Arrhenius parameters.

\begin{tabular}{ccccccccc}
\hline Rate & \multicolumn{9}{c}{ Reaction Temperature $\left({ }^{\circ} \mathrm{C}\right)$} & & \multicolumn{2}{c}{ Arrhenius Parameters } \\
\cline { 2 - 5 } Constant & 80 & 90 & 100 & 110 & 120 & & $\mathrm{~A}$ & $E a / R$ \\
\hline$k_{1}$ & $6.00 \times 10^{-4}$ & $8.00 \times 10^{-4}$ & $7.00 \times 10^{-4}$ & $8.00 \times 10^{-4}$ & $1.00 \times 10^{-3}$ & & $6.66 \times 10^{-2}$ & 1676.2 \\
$k_{3}$ & $9.00 \times 10^{-4}$ & $9.00 \times 10^{-4}$ & $6.00 \times 10^{-4}$ & $2.00 \times 10^{-4}$ & 0.00 & & $9.82 \times 10^{-12}$ & -6565.2 \\
$k_{4}$ & $2.00 \times 10^{-4}$ & 0.00 & 0.00 & 0.00 & 0.00 & & $\mathrm{n} / \mathrm{a}$ & $\mathrm{n} / \mathrm{a}$ \\
$k_{5}$ & $1.26 \times 10^{-2}$ & $9.10 \times 10^{-3}$ & $5.20 \times 10^{-3}$ & $3.40 \times 10^{-3}$ & $1.70 \times 10^{-3}$ & & $4.63 \times 10^{-11}$ & -6897.2 \\
$k_{6}$ & $2.10 \times 10^{-3}$ & $1.00 \times 10^{-3}$ & $4.00 \times 10^{-4}$ & 0.00 & 0.00 & & $8.38 \times 10^{-17}$ & -10904 \\
\hline
\end{tabular}


ating conditions. We conclude that this temperature was not enough to initiate the glycerolysis-interesterification process. Thus, the calculation of rate constants was only based on the higher temperature data $\left(80-120{ }^{\circ} \mathrm{C}\right)$ using Equations (5) to (8). As we assumed that the reversible reaction in equation (1) is neglected, the calculation of $k_{2}$ was also dismissed (Table $3)$.

The rate constants, $k_{1}, k_{3}$, and $k_{5}$ showed the product formation in Equations (1), (2), and (3). While rate constants $k_{4}$ and $k_{6}$ showed the reverse reaction (reactant formation) for Equations (2) and (3), respectively. From data obtained in Table 3 , it could be seen that equation (2) was mainly irreversible, while Equation (3) was reversible only at a lower temperature. These results probably correlated to the usage of higher temperatures for the experimental procedure.

The high temperature helps to improve the mass transfer between oil and glycerol. Since oil and glycerol are viscous fluids at room temperature and they are immiscible, increasing the reaction temperature can drop the fluid's viscosity and improve the reaction between oil and glycerol [32]. Moreover, high temperature increases the kinetic energy between molecules, thus the intermolecular movement will increase and lead to a faster diffusion [33].

Glycerolysis also follows endothermic reaction and usually occurs at high temperatures [34-36]. According to Le Chatelier's principle, temperature affects the reaction equilibrium, which the higher the temperature, the more the reaction leads to the formation of products [37]. Thus, the reaction towards reactant formation will be minimal, and at some point, may lead to an irreversible reaction.

Since equation (1) was the initial reaction, it was assumed that this reaction was irreversible. Thus the calculation was only based on the product formation. The reaction constants for the reversible reaction in equations (2) and (3) were calculated. For those reactions, the reaction to generate products was more remarkable than product degradation to form the reactants. It is supported by the values of $k_{3}$ and $k_{5}$, which were greater than that of $k_{4}$ and $k_{6}$. Thus, all reactions contribute to the MAG and DAG product formation. The most influential reaction on the product formation was the Equation (3). It is proved by the highest reaction rate constant value $\left(k_{5}\right)$ and the higher yield of DAG product than MAG at any reaction temperature. This issue is most likely happened due to the excess of TAG in the reactants and the accumulation of MAG over time, which shifts the reaction's equilibrium toward DAG formation, as reported by Moquin et al. [38].

The Arrhenius equation demonstrates the correlation between temperature and the reaction rate constant, as stated in equation (9). Since the value of $k_{4}$ (Table 3) was mostly zero for reaction at temperature 90 to $120^{\circ} \mathrm{C}$, it can be concluded that reaction (2) is irreversible. Thus the Arrhenius equation for $k_{4}$ was neglected. Therefore, the calculation of the Arrhenius constant and activation energy value was only based on $k_{1}, k_{3}, k_{5}$, and $k_{6}$ (Table 3 ).

From Table 3, it could be seen that the value of activation energy for $k_{3}, k_{5}$, and $k_{6}$ was negative, while $k_{1}$ was the only one that had a positive value. Since the activation energy value is less likely to be less than zero, it could be assumed that an intermediate complex could be formed during these reactions. Mozurkewich and Benson [39] explained that a tight transition state with low potential energy must be achieved to obtain a negative activation energy $(E a<0)$. This condition could be accomplished if the reaction undergoes a stable intermediate. The activation energy $(E a)$ is formed by the energy of transition state $\left(E_{T S}\right)$ subtracted with the energy of reactant $\left(E_{R}\right)$. At lower temperatures, the average energy of the transition state was lower than the average energy of the reactant, resulting in a negative value of activation energy. Nevertheless, in glycerolysisinteresterification, the activation energy for $k_{1}$ is the most important since it was the initial reaction.

\subsection{Reaction Kinetics Model Evaluation}

Figure 4 shows the experimental data of glycerolysis-interesterification compared to the kinetic model from the differential equation and Arrhenius parameters substitution. The difference between the experimental data and kinetic models for reaction temperature 120 , $110,100,90$, and $80{ }^{\circ} \mathrm{C}$ were $1.00 \times 10^{-2}$, $1.00 \times 10^{-2}, 2.00 \times 10^{-2}, 3.00 \times 10^{-2}$, and $3.00 \times 10^{-2}$, respectively. The difference of the kinetic model between the differential equation and Arrhenius parameters substitute were $4.00 \times 10^{-8}$, $9.00 \times 10^{-8}, 4.00 \times 10^{-8}, 6.00 \times 10^{-7}$, and $2.56 \times 10^{-6}$, respectively.

Kinetic models usually have a slight difference from the experimental data. Lionelli [40] explained that data are results of interactions between researchers and the world which are then processed as usable evidence to claim about a certain phenomenon, while models are conceptualized as representations of data. Data and models correspond to each other as they 
are a representation of the real condition and proposed theory, respectively, with data being closer to real condition phenomena and models being closer to theory. Thus, connecting the theory and real conditions using the relation between experimental data and models would likely create a missing gap.
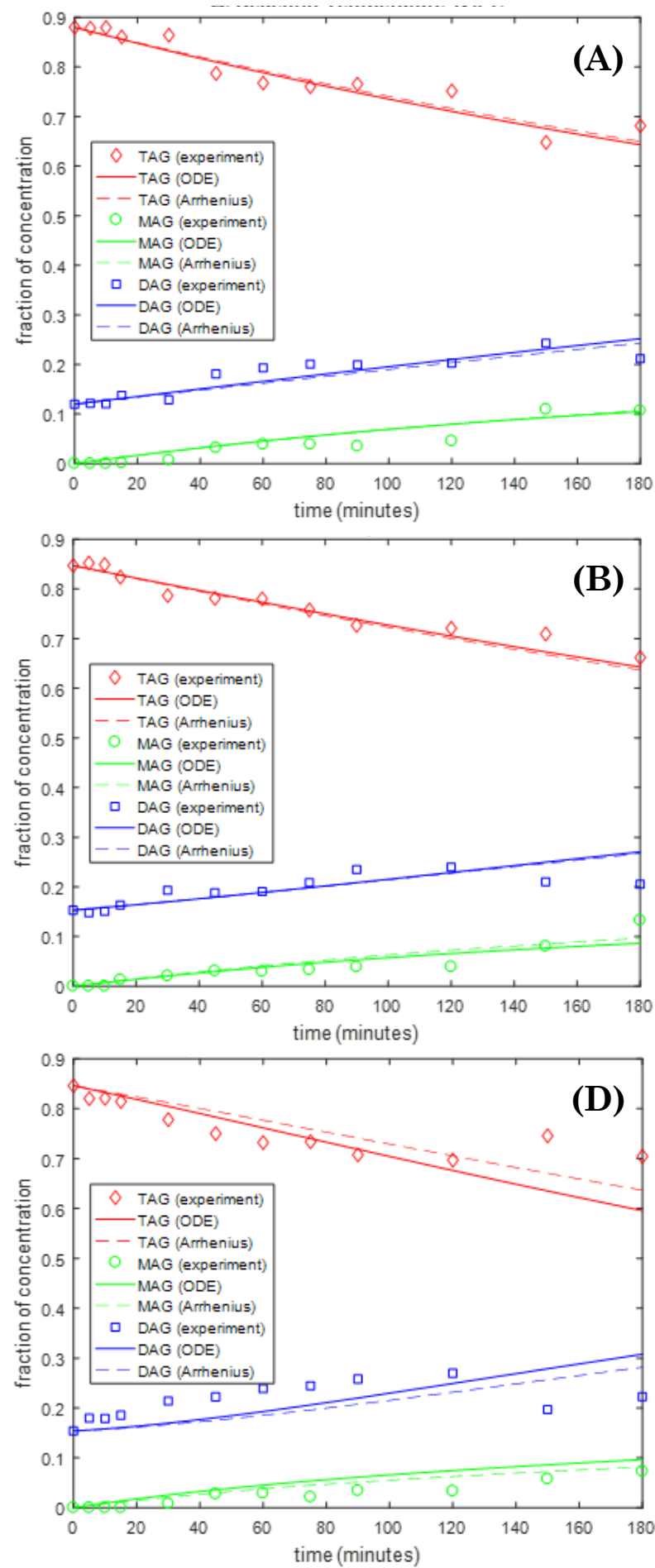

\section{Conclusion}

Activation of sodium silicate resulted in reduction of $\mathrm{Si}-\mathrm{O}$ bending. It shifted to a $\mathrm{Si}-\mathrm{O}-\mathrm{Na}$ and $\mathrm{Si}-\mathrm{O}-\mathrm{Si}$ functional groups, which were shown by a sharp downward peak at $\sim 1000 \mathrm{~cm}^{-1}$ and $\sim 890 \mathrm{~cm}^{-1}$, respectively. MAG content was not produced at $70^{\circ} \mathrm{C}$. However, the temperature has a significant effect on SLs at higher than $90^{\circ} \mathrm{C}$. The best condition for this reaction was at $110{ }^{\circ} \mathrm{C}$. TAG, MAG, and DAG were up to $65 \%, 10 \%$, and $25 \%$, respectively at $110{ }^{\circ} \mathrm{C}$ and above. SLs products had SMP and MP 1.34-1.46 times and 1.361.52 times higher than the PS-PO blend, respectively. It showed a drastic increase in the hardness value than PS-PO blend ranging from 4.65 to 15.90 -fold. Furthermore, MP and hardness value at $120{ }^{\circ} \mathrm{C}$ were significantly lower than the value at $110^{\circ} \mathrm{C}$. It is because of random interesterification between TAG of PS and TAG of PO in this system. Besides, kinetic
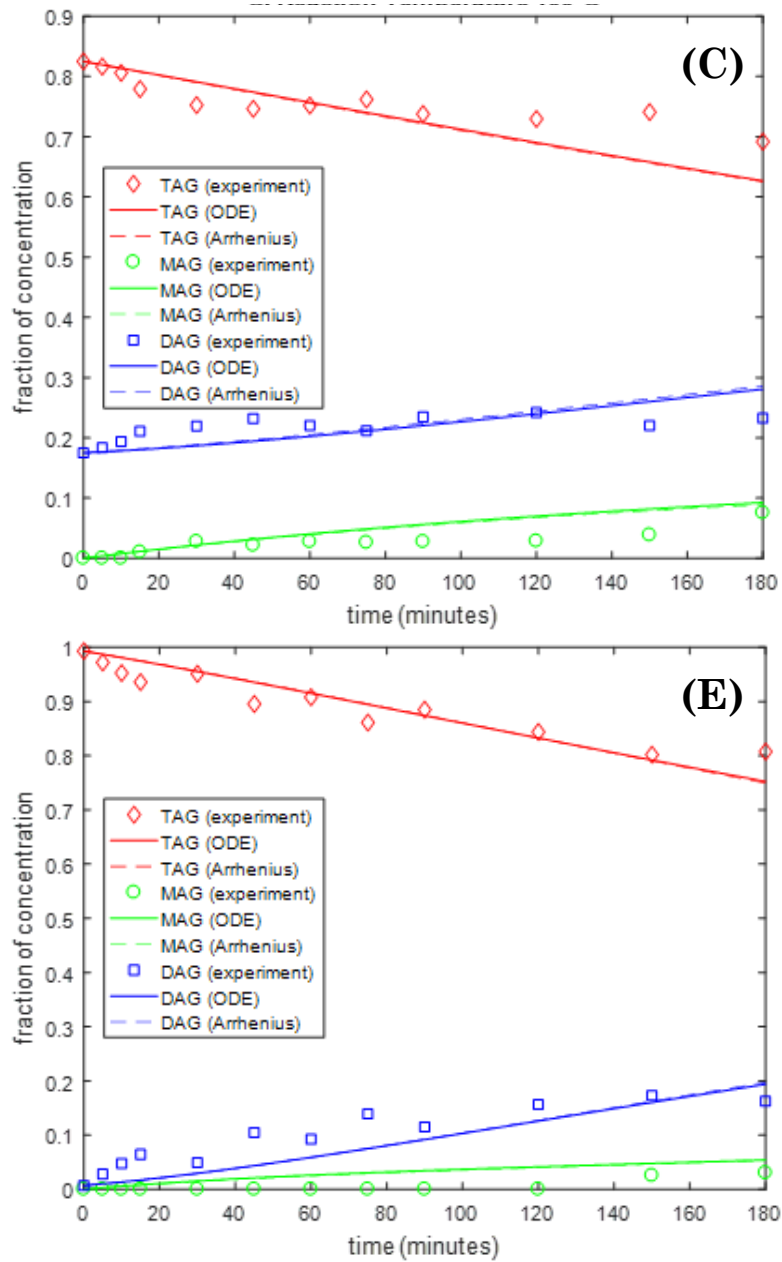

Figure 4. Reaction kinetic model of TAG, MAG, and DAG at reaction temperature $120^{\circ} \mathrm{C}(\mathrm{A}), 110{ }^{\circ} \mathrm{C}$ (B), $100{ }^{\circ} \mathrm{C}(\mathrm{C}), 90^{\circ} \mathrm{C}(\mathrm{D})$, and $80^{\circ} \mathrm{C}(\mathrm{E})$. 'Experiment' represents the experimental data, 'ODE' represents the model from differential equations, and 'Arrhenius' represents the model using Arrhenius parameters substitution. 
models implied that the reaction could be irreversible at a higher temperature. Equation (3) is the dominant reaction in glycerolysisinteresterification, which leads to a higher content of DAG than MAG in the end product. In summary, glycerolysis-interesterification of PSPO blend for producing SLs using the activated sodium silicate as catalyst improved MP, SMP, and hardness of SLs due to an increase in MAG and DAG content at a higher temperature.

\section{Acknowledgments}

This research was funded by the Ministry of Research and Technology / National Research and Innovation Agency of Republic Indonesia (RISTEK-BRIN) Research Grant "Program Menuju Doktor Sarjana Unggul (PMDSU) Batch III". Contract Number: 2972/UN1.DITLIT/DIT-LIT/LT/2019.

\section{References}

[1] Kim, B.H., Akoh, C.C. (2015). Recent Research Trends on the Enzymatic Synthesis of Structured Lipids. Journal of Food Science, 80(8), 1713-1724. DOI: 10.1111/17503841.12953.

[2] Naik, M.K., Naik, S.N., Mohanty, S. (2014). Enzymatic Glycerolysis for Conversion of Sunflower Oil to Food Based Emulsifiers. Catalysis Today, 237, 145-149. DOI: 10.1016/j.cattod.2013.11.005.

[3] Zhong, N., Cheong, L.Z., Xu, X. (2014). Strategies to obtain high content of monoacylglycerols. European Journal of Lipid Science and Technology, 116, 97-107. DOI: 10.1002/EJLT.201300336.

[4] Feltes, M.M.C., de Oliveira, D., Block, J.M., Ninow, J.L. (2012). The Production, Benefits, and Applications of Monoacylglycerols and Diacylglycerols of Nutritional Interest. Food and Bioprocess Technology, 6, 17-35. DOI: 10.1007/s11947-012-0836-3.

[5] Subroto, E., Supriyanto, S., Utami, T., Hidayat, C. (2018). Enzymatic glycerolysisinteresterification of palm stearin-olein blend for synthesis structured lipid containing high mono- and diacylglycerol. Food Science and Biotechnology, 28(2), 511-517. DOI: 10.1007/s10068-018-0462-6.

[6] Subroto, E., Wisamputri, M.F., Supriyanto, S., Utami, T., Hidayat, C. (2020). Enzymatic and chemical synthesis of high mono- and diacylglycerol from palm stearin and olein blend at different type of reactor stirrers. Journal of the Saudi Society of Agricultural Sciences, 19(1), 31-36. DOI: 10.1016/j.jssas.2018.05.003.
[7] Reyniers, M.F., Marin, G.B. (2014). Experimental and Theoretical Methods in Kinetic Studies of Heterogeneously Catalyzed Reactions. Annual Review of Chemical and Biomolecular Engineering, 5, 563-594. DOI: 10.1146/annurev-chembioeng-060713-040032.

[8] Daramola, M.O., Nkazi, D., Mtshali, K. (2015). Synthesis and Evaluation of Catalytic Activity of Calcined Sodium Silicate for Transesterification of Waste Cooking Oil to Biodiesel. International Journal of Renewable Energy Research, 5(2), 517-523. DOI: 10.20508/ijrer.v5i2.2164.g6606

[9] Okullo, A.A., Temu, A.K. (2015). Modelling the Kinetics of Jatropha Oil Transesterification. Energy and Power Engineering, 7, 135143. DOI: $10.4236 /$ epe.2015.74013.

[10] Vallance, C. (2017). Rate laws: relating the reaction rate to reactant concentrations. In An Introduction to Chemical Kinetics. California: Morgan \& Claypool Publishers.

[11] Darnoko, D., Cheryan, M. (2000). Kinetics of Palm Oil Transesterification in a Batch Reactor. Journal of the American Oil Chemists' Society, 77(12), 1263-1267. DOI: 10.1007/s11746-000-0198-y.

[12] Kumoro, A.C. (2012). Experimental and Modeling Studies of the Reaction Kinetics of Alkaline-Catalyzed Used Frying Oil Glycerolysis using Isopropyl Alcohol as a Reaction Solvent. Research Journal of Applied Sciences, Engineering and Technology, 4(8), 869-876.

[13] Solaesa, A.G., Sanz, M.T., Beltran, S., Melgosa, R. (2016). Kinetic study and kinetic parameters of lipase-catalyzed glycerolysis of sardine oil in a homogeneous medium. Chinese Journal of Catalysis, 37, 596-606. DOI: 10.1016/S1872-2067(15)61040-3.

[14] Voll, F., Kruger, R.L., Castilhos, F., Filho, L.C., Cabral, V., Ninow, J., Corazza, M.L. (2011). Kinetic modeling of lipase-catalyzed glycerolysis of olive oil. Biochemical Engineering Journal, 56, 107-115. DOI: 10.1016/j.bej.2010.11.005.

[15] Moquin, P.H.L., Temelli, F., King, J.W., Palcic, M.M. (2005). Kinetic Modeling of the Glycerolysis Reaction for Soybean Oils in Supercritical Carbon Dioxide Media. Journal of the American Oil Chemists' Society, 82(2), 613-617. DOI: 10.1007/s11746-005-1118-x.

[16] Zhong, N., Deng, X., Huang, J., Xu, L., Hu, K., Gao, Y. (2014). Low-temperature chemical glycerolysis to produce diacylglycerols by heterogeneous base catalyst. European Journal of Lipid Science and Technology, 116(4), 470476. DOI: 10.1002/ejlt.201300438. 
[17] Corma, A., Iborra, S., Miquel, S., Primo, J. (1998). Catalysts for the Production of Fine Chemicals: Production of Food Emulsifiers, Monoglycerides, by Glycerolysis of Fats with Solid Base Catalysts. Journal of Catalyst, 173, 315-321. DOI: 10.1006/JCAT.1997.1930.

[18] Zhang, Z., Ma, X., Wang, Y., Yan, R., Liu, M. (2014). Production of Monoacylglycerols from Fully Hydrogenated Palm Oil Catalyzed by Hydrotalcite Loaded with K2CO3. Chemical Engineering Communications, 202(5), 585592. DOI: 10.1080/00986445.2013.853294.

[19] Guo, F., Peng, Z.G., Dai, J.Y., Xiu, Z.L. (2010). Calcined sodium silicate as solid base catalyst for biodiesel production. Fuel Processing Technology, $91, \quad 322-328$. D O I : 10.1016/j.fuproc.2009.11.003.

[20] Perdana, I., Nugrahanti, N., Sofiyah, S., Bendiyasa, I.M. (2016). Transesterification of palm oil using sodium silicate base catalyst from geothermal sludge. IOP Conference Series: Materials Science and Engineering, 162, 012-024. DOI: $10.1088 / 1757$ $899 \mathrm{X} / 162 / 1 / 012024$

[21] Tanabe, K., Yamaguchi, T. (1963). Basicity and Acidity of Solid Surfaces. Journal of the Research Institute for Catalysis Hokkaido University, 11(3), 179-184.

[22] Anggoro, D.D., Buchori, L., Sumantri, I., Oktavianty, H. (2019). Preparation and characterization of $\mathrm{KF} / \mathrm{CaO}-\mathrm{MgO}$ catalyst for monoglycerides synthesis. Malaysian Journal of Fundamental and Applied Sciences, 15(5), 640-643. DOI: 10.11113/mjfas.v15n5.1243.

[23] AOCS. (1997). Official and Tentative Methods of the American Oil Chemist's Society, 7th Ed. Champaign, Illinois: American Oil Chemist's Society Press USA.

[24] Coates, J. (2006). Interpretation of Infrared Spectra, A Practical Approach. In Encyclopedia of Analytical Chemistry. Chichester: John Wiley \& Sons, Ltd. DOI: 10.1002/9780470027318.a5606.

[25] Guo, F., Wei, N.N., Xiu, Z.L., Fang, Z. (2012). Transesterification mechanism of soybean oil to biodiesel catalyzed by calcined sodium silicate. Fuel, 93, 468-472. DOI: 10.1016/j.fuel.2011.08.064.

[26] Xie, W., Peng, H., Chen, L. (2006). Calcined $\mathrm{Mg}-\mathrm{Al}$ hydrotalcites as solid base catalysts for methanolysis of soybean oil. Journal of Molecular Catalysis A: Chemical, 246, 24-32. DOI: $10.1016 /$ j.molcata.2005.10.008.

[27] Dijkstra, A.J. (2020). Some Thoughts on the Mechanism of Ester Interchange Reactions Involving Acylglycerols. European Journal of Lipid Science and Technology, 122, 1-7. DOI: 10.1002/ejlt.202000188.
[28] Zhong, N., Li, L., Xu, X., Cheong, L.Z., Xu, Z., $\mathrm{Li}$, B. (2013). High yield of monoacylglycerols production through low-temperature chemical and enzymatic glycerolysis. European Journal of Lipid Science and Technology, $115(6), \quad 684-690$. D O I : 10.1002/ejlt.201200377.

[29] Aini, I.N., Miskandar, M.S. (2007). Utilization of palm oil and palm products in shortenings and margarines. European Journal of Lipid Science and Technology, 109, 422-432. DOI: 10.1002/ejlt.200600232.

[30] Kellens, M., Gibon, V., Hendrix, M., Greyt, W.D. (2007). Palm oil fractionation. European Journal of Lipid Science and Technology, 109, 336-349. DOI: 10.1002/ejlt.200600309.

[31] Soares, F.A.S.D.M., da Silva, R.C., da Silva, K.C.G., Lourenco, M.B., Soares, D.F., Gioielli, L.A. (2009). Effects of chemical interesterification on physicochemical properties of blends of palm stearin and palm olein. Food Research International, 42, 1287-1294. DOI: 10.1016/j.foodres.2009.03.022.

[32] Gulyaev, I.P., Soloneko, O.P. (2013). Hollow droplets impacting onto a solid surface. Experiments in Fluids, 54(1432), 1-12. DOI: 10.1007/s00348-012-1432-z.

[33] Jia, D., Hamilton, J., Zaman, L.M., Goonewardene, A. (2007). The time, size, viscosity, and temperature dependence of the Brownian motion of polystyrene microspheres. American Journal of Physics, 75(2), 111-115. DOI: 10.1119/1.2386163.

[34] Dijon, A. (2015). Microwave-irradiated zinc chloride catalyzed glycerolysis of high free fatty acid vegetable oil. Master Thesis, Gokongwei College of Engineering, De La Salle University.

[35] Gole, V.L., Gogate, P.R. (2014). Intensification of glycerolysis reaction of higher free fatty acid containing sustainable feedstock using microwave irradiation. Fuel Processing Technology, $118, \quad 110-116$. D O I : 10.1016/j.fuproc.2013.08.018.

[36] Satriana, S., Supardan, M.D. (2008). Kinetic Study of Esterification of Free Fatty Acid in Low Grade Crude Palm Oil using Sulfuric Acid. ASEAN Journal of Chemical Engineering, 8(1), 1-8. DOI: 10.22146/ajche.50112.

[37] Susanti, R.F., Kim, J., Yoo, K. (2014). Supercritical Water Gasification for Hydrogen Production. In Supercritical Fluid Technology for Energy and Environmental Applications. Oxford: Elsevier B.V. DOI: 10.1016/B978-0-44462696-7.00006-X. 
[38] Moquin, P.H.L., Temelli, F., King, J.W., Palcic, M.M. (2005). Kinetic Modeling of the Glycerolysis Reaction for Soybean Oils in Supercritical Carbon Dioxide Media. Journal of the American Oil Chemists' Society, 82(2), 613-617. DOI: 10.1007/s11746-005-1118-x.

[39] Mozurkewich, M., Benson, S.W. (1984). Negative Activation Energies and Curved Arrhenius Plots. 1. Theory of Reactions over Potential Wells. The Journal of Physical Chemistry A, 88, 6429-6435. DOI: 10.1021/j150669a073.
[40] Lionelli, S. (2019). What distinguishes data from models?. European Journal for Philosophy of Science, 9(22), 1-27. DOI: 10.1007/s13194-018-0246-0. 